\title{
Optimalisasi Konektivitas Antara Stasiun Cakung dan Pasar Bintara
}

\author{
Telly Rosdiyani ${ }^{1, *}$, Dasa Aprisandi ${ }^{1}$ \\ Program Studi Teknik Sipil, Universitas Banten Jaya, Serang ${ }^{1}$ \\ Koresponden*,Email: tellyrosdiyani004@gmail.com
}

\begin{tabular}{lcl}
\hline & Info Artikel & Abstract \\
\hline Diajukan & 09 Juli 2021 & Bintara Market is a traditional market in the village area of Bintara Bekasi City. Uniquely, \\
Diperbaiki & 01 November 2021 & this market is located opposite Cakung Railway Station in Pulogebang Village, East Jakarta. \\
Disetujui & 09 November 2021 & Visibly, it still looks chaotic that the arrangement of the parking lot interferes with the trip. \\
& This study aims to find out how to optimize parking management, How much it costs for \\
& optimization, what is the potential contribution of levy revenue after optimization, and how \\
& the connectivity masterplan between Cakung Station and Bintara Market. The data required \\
& for vehicle survey, cross-persons and levy obtained by 8 surveyors who have been placed, \\
& then processing data along with supporting materials in the MS-exsel comfilation to obtain \\
& parking characteristics, see the amount of contribution of parking levy per day and can \\
& determine the type of connectivity design. The results of the study obtained the addition of \\
& 850 motorcycle parking spaces and 250 SRP car parking, as well as potential parking \\
& revenue of Rp 3,860,000,-/day, the design of connectivity between statsiun Cakung-Bintara \\
Keywords: Connectivity, Optimization, & market by using zebra cross with connectivity optimization costs of Rp 2,159,036,425,-.
\end{tabular}

\begin{abstract}
Abstrak
Pasar Bintara suatu pasar tradisional di wilayah kelurahan Bintara kota Bekasi. Uniknya, pasar ini berada di seberang stasiun kereta api Cakung wilayah kelurahan Pulogebang kota Jakarta Timur. Secara visual masih terlihat semrawut penataan lahan parkir mengganggu perjalanan. Penelitian ini bertujuan mengetahui bagaimana optimalisasi pengelolaan parkir, Berapa biaya yang diperlukan untuk optimalisasi, berapa potensi kontribusi pendapatan retribusi setelah dilakukan optimalisasi, dan bagaimana masterplan konektivitas antara stasiun Cakung dan pasar Bintara. Data yang diperlukan survei kendaran, penyebrangan orang serta retribusi didapatkan oleh 8 orang surveyor yang telah ditempatkan, selanjutnya pengolahan data beserta bahan pendukung di kompilasikan MS-exsel untuk mendapatkan karakteristik parkir, jumlah kontribusi retribusi parkir perhari dan dapat menetapkan jenis design konektifitas. Hasil penelitian didapatkan penambahan ruang parkir motor 850 dan parkir mobil 250 SRP, serta potensi pendapatan parkir sebesar Rp $\mathbf{3 . 8 6 0 . 0 0 0}$,-/hari, desain konektivitas antara stasiun Cakung - pasar Bintara dengan menggunakan zebra cross dengan biaya optimalisasi konektivitasnya sebesar $\operatorname{Rp} 2.159 .036 .425,-$
\end{abstract}

Kata kunci: Konektivitas, Optimalisasi, Ruang Parkir, Zebra Cross

milik warga disekitar stasiun yang dikelola secara pribadi dengan biaya penitipan lima ribu rupiah untuk sekali parkir tanpa jaminan keamanan [4]. Dengan demikian pengunjung lebih memilih menitipkan kendaraan pribadinya di pasar Bintara dengan biaya yang relatif terjangkau dan keamanan yang lebih terjamin. Hasil dari retribusi parkir pasar Bintara ini diharapkan dapat meningkatkan pendapatan daerah kota Bekasi, serta dapat meningkatkan pelayanan kepada masyarakat. Berdasarkan penjelasan diatas penelitian ini bertujuan untuk mengetahui perencanaan optimalisasi manajemen parkir, perencanaan biaya, dan pendapatan yang dapat diraih oleh pengelola, serta perencanaan konektivitas yang tepat sebagai penghubung pasar Bintara dengan stasiun Cakung.

\section{Metode}


Lokasi pengamatan dilakukan di pasar Bintara yang berada di kelurahan Bintara kota Bekasi propinsi Jawa Barat dan stasiun Cakung yang tidak jauh dari lokasi pasar tersebut. Survei kendaraan dilakukan $12 \mathrm{jam} / \mathrm{hari}$ dari jam $06.00 \mathrm{~s} / \mathrm{d}$ 18.00, selama 3 hari (sabtu, minggu dan senin) oleh delapan surveyor dengan pembagian lokasi ditunjukkan pada Gambar 1.

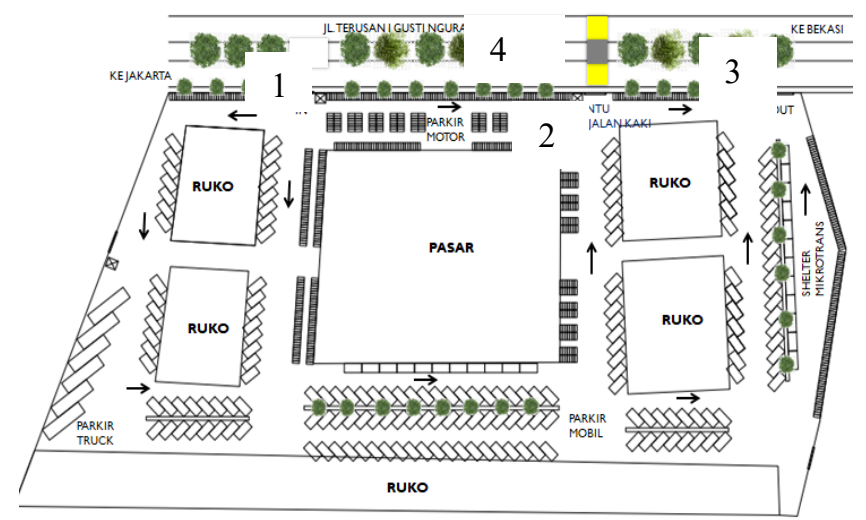

Gambar 1. Layout Pasar Bintara

Berdasarkan Gambar 1, dapat dijelaskan distribusi penempatan surveyor pada empat lokasi yaitu lokasi 1 ditempatkan dua orang pada gerbang pintu masuk pasar untuk mencatat kendaraan keluar masuk pasar, lokasi 2 ditempatkan dua orang di pasar Bintara yang bertugas untuk mengamati/mencatat arus kendaraan dan penyebrang jalan dari arah pasar-stasiun, lokasi 3 gerbang pintu keluar pasar ditempatkan dua orang lagi untuk mencatat kendaraan keluar masuk pasar dan lokasi 4 ditempatkan dua orang didepan pasar untuk mengamati/mencatat yang menyebrang jalan arah stasiun-pasar.

\section{Pengumpulan Data}

Data yang diperlukan berupa data primer dan data sekunder. Data primer merupakan data yang diperoleh dari hasil pengamatan dilapangan dengan melakukan survei arus lalu lintas, sedangkan data sekunder didapatkan dengan mencari informasi ke Dinas Perhubungan kota Bekasi. Data diperoleh dari hasil survei adalah sebagai berikut [5][6]:
a. Jenis dan Volume kendaraan
b. Jumlah penyebrang orang
c. Waktu kedatangan dan keluar area parkir beserta nomor plat kendaraannya

d. Data teknis jalan

Jumlah surveyor yang dibutuhkan untuk melakukan pengamatan adalah sebagai berikut: surveyor volume parkir (2orang $\times 2$ titik $=4$ orang), surveyor volume penyebrangan orang ( 2 orang $\mathrm{x} 1$ titik $=2$ orang) arah pasar-stasiun, surveyor arus lalu lintas ( 2 orang x 1 titik $=2$ orang) arah stasiun-pasar.

\section{Alur Penelitian}

Penelitian dimulai dengan menetapkan terlebih dahulu tujuan dan metode yang akan dilakukan selanjutnya mempersiapkan formulir survei yang dibutuhkan untuk pengumpulan data primer maupun data skunder lainnya, data yang sudah didapatkan kemudian dianalisis untuk mengetahui pengelolaan parkir pasar Bintara dengan menganalisis karakteristik parkirnya [7], terdiri dari akumulasi parkir, durasi parkir, tingkat pergantian parkir, kapasitas parkir, indeks parkir, kebutuhan ruang parkir [8][9]. Analisis dilanjutkan dengan penentuan desain fasilitas penyebrangan orang yang tepat berdasarkan metode Departemen Jendral Bina Marga [2][10]. Penganalisaan kebutuhan biaya optimalisasi berdasarkan analisis biaya setiap sub kegiatan yang diperlukan. Adapun gambar alir penelitian dapat disajikan pada Gambar 2.

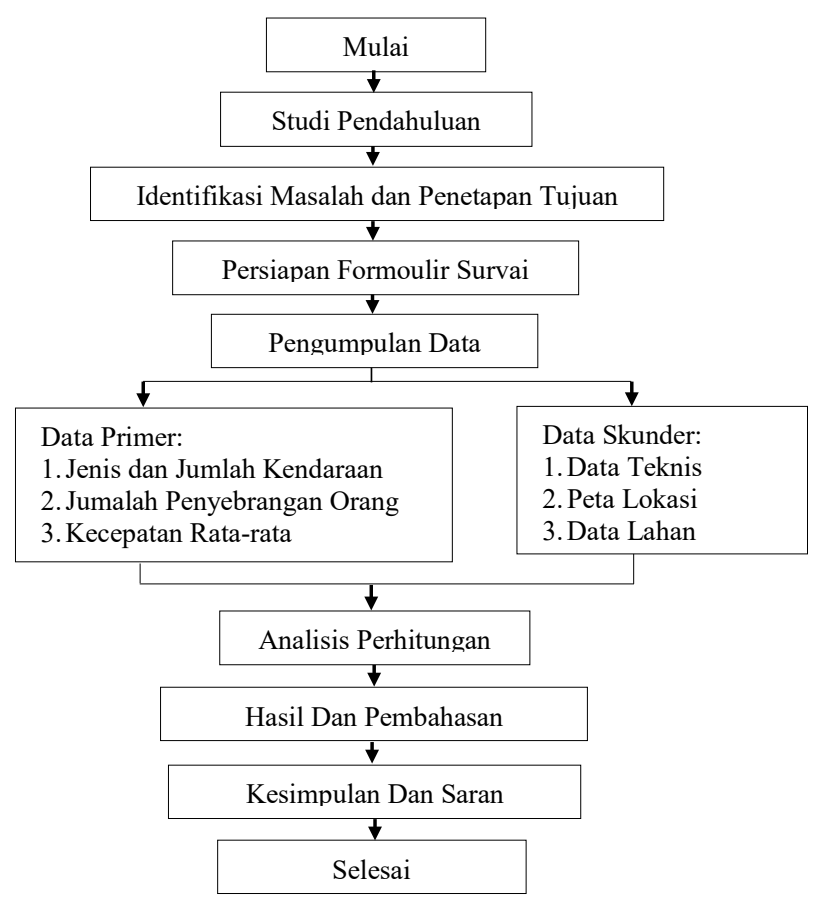

Gambar 2. Diagram Alir Penelitian

1. Akumulasi parkir dihitung dengan persamaan 1:

Akumulasi $=Q_{\text {in }}-Q_{\text {out }}+Q_{s}$

dimana:

$Q_{i n} \quad=$ Kendaraan yang masuk lokasi parkir

$Q_{\text {out }}=$ Kendaraan yang keluar lokasi parkir

$Q_{s} \quad=$ Kendaraan yang sudah ada di lokasi parkir sebelum pengamatan di lakukan 
2. Durasi parkir dihitung dengan persamaan 2:

$$
\mathrm{D}=\frac{\sum \mathrm{f} \cdot \mathrm{x}}{\sum \mathrm{f}}
$$

dimana:

$$
\begin{array}{lll}
\mathrm{D} & = & \text { Rata-rata lamanya kendaraan parkir atau } \\
& \text { durasi (jam/kend) }
\end{array}
$$

3. Tingkat pergantian parkir dihitung persamaan 3:

$$
\mathrm{TR}=\frac{\mathrm{Nt}}{(\mathrm{s}) \mathrm{x}(\mathrm{Ts})}
$$

$$
\begin{array}{lll}
\text { dimana: } & \\
\mathrm{TR} & = & \begin{array}{l}
\text { Angka pergantian parkir } \\
\text { (kendaraan/petak/jam) }
\end{array} \\
\mathrm{S} & = & \text { Jumlah total stall/petak resmi (petak) } \\
\mathrm{Ts} & = & \text { Lamanya periode survei (jam) } \\
\mathrm{Nt} & = & \text { Jumlah total kendaraan pada saat } \\
& & \text { dilaksanakan survei (kendaraan) }
\end{array}
$$

4. Kapasitas Parkir dihitung dengan persamaan 4:

$$
\mathrm{KP}=\frac{S}{D}
$$

\section{dimana :}

$$
\begin{array}{lll}
\mathrm{KP} & = & \text { Kapasitas parkir }(\mathrm{SRP} / \mathrm{Kend} / \mathrm{Jam}) \\
S & = & \text { Jumlah Petak Parkir yang tersedia di } \\
& \text { lokasi penelitian } \\
D & = & \text { Rata-rata lamanya parkir }(\mathrm{jam} / \mathrm{kend})
\end{array}
$$

5. Indeks Parkir dihitung dengan persamaan 5:

$\mathrm{IP}=\frac{\text { Akumulasi Parkir }}{\text { Petak Parkir Tersedia }} \times 100 \%$

6. Kebutuhan ruang Parkir dihitung dengan persamaan 6:

$\mathrm{S}=\frac{N t . D}{T . f}$

\section{dimana:}

$$
\begin{aligned}
& \mathrm{S}=\text { Jumlah petak parkir yang diperlukan saat } \\
& \text { ini } \\
& \mathrm{Nr}=\text { Jumlah total kendaraan selama waktu } \\
& \text { Survei (kend) } \\
& D \quad=\text { Waktu rata-rata lamanya parkir } \\
& \text { (jam/kend) } \\
& T=\text { Lamanya survei (jam) } \\
& f=\text { Faktor pengurangan akibat pergantian } \\
& \text { parkir, nilai antara } 0.85 \mathrm{~s} / \mathrm{d} 0.95 \\
& \text { kapasitas ruas jalan. }
\end{aligned}
$$

Penentuan desain fasilitas penyebrangan orang berdasarkan jumlah penyebrang orang antara 100-1250 dengan volume kendaraan 2000-5000 maka ditentukan menggunakan tipe fasilitas Zebra Cross (Zc) [11].

\section{Hasil dan Pembahasan \\ Karakteristik Parkir}

Hasil data dari survei kendaraan yang dilakukan oleh 8 surveyor yang ditempatkan pada pintu gerbang masuk atau keluar pasar Bintara kemudian dikompilasi menggunakan MS-exsel bertujuan untuk mengetahui karakteristik parkir dan mengetahui optimalisasi konektivitas pasar Bintara dengan stasiun Cawang. Penelitian parkir ini sudah banyak dilakukan oleh peneliti sebelumnya seperti peneliti S. dan I. B. Mariani dan Stupa [5][9], namun untuk penelitian kali ini memiliki permasalahan bagaimana upaya untuk mengoptimalisasikan konektivitas, seperti yang telah dipaparkan pada latar belakang sebelumnya. Adapun luas bangunan parkir pasar Bintara dapat dilihat di Gambar 3.

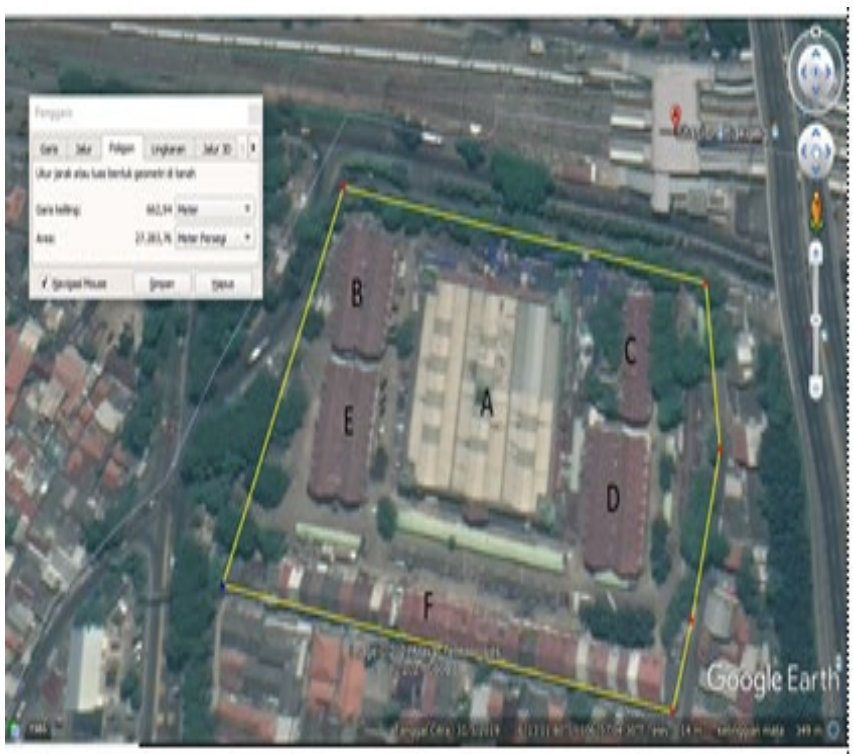

Berdasarkan Gambar 3, luas bangunan ruang parkir pasar Bintara dapat dilihat pada Tabel 1.

Tabel 1. Luas Bangunan Parkir Pasar Bintara

\begin{tabular}{ccccc}
\hline No & Bangunan & $\begin{array}{c}\text { Panjang } \\
(\text { meter })\end{array}$ & $\begin{array}{c}\text { Lebar } \\
(\text { meter })\end{array}$ & $\begin{array}{c}\text { Luas } \\
\left(\mathrm{m}^{2}\right)\end{array}$ \\
\hline 1 & $\mathrm{~A}$ & 70 & 70 & 4900 \\
2 & $\mathrm{~B}$ & 40 & 25 & 1000 \\
3 & $\mathrm{C}$ & 40 & 25 & 1000 \\
4 & $\mathrm{D}$ & 40 & 25 & 1000 \\
5 & $\mathrm{E}$ & 40 & 25 & 1000 \\
6 & $\mathrm{~F}$ & 180 & 20 & 1800 \\
\multicolumn{4}{c}{ Jumlah Total } \\
\hline
\end{tabular}


Berdasarkan data luas bangunan pada Tabel 1, luas total bangunan sebesar $10700 \mathrm{~m}^{2}$, maka luas lahan yang digunakan parkir didapatkan sebesar luas keseluruhan dikurangi luas total bangunan yaitu $27,283.76 \mathrm{~m}^{2}-10,700$ $\mathrm{m}^{2}=16,583,76 \mathrm{~m}^{2}$.

\section{a. Akumulasi Parkir}

Akumulasi parkir merupakan nilai yang digunakan untuk mengetahui jumlah kendaraan yang sedang berada pada suatu lahan parkir pada selang waktu tertentu.

Kedatangan/keberangkatan kendaraan di lokasi parkir itu tidak sama, sehingga untuk memudahkan analisa periodenya dibuat dalam interval 15 menitan pada jam 06:00-18:00 di tampilkan pada Tabel 2.

Tabel 2. Rekapitulasi Akumulasi Parkir Sepeda Motor

\begin{tabular}{lllccc}
\hline \multicolumn{2}{c}{ Interval } & \multicolumn{3}{c}{ Akumulasi Parkir Pada Hari } \\
\multicolumn{2}{c}{} & & Sabtu & Minggu & Senin \\
\hline 6,00 & - & 7,00 & 99 & 43 & 124 \\
7,00 & - & 8,00 & 96 & 43 & 131 \\
8,00 & - & 9,00 & 90 & 36 & 142 \\
9,00 & - & 10,00 & 74 & 41 & 160 \\
10,00 & - & 11,00 & 62 & 33 & 187 \\
11,00 & - & 12,00 & 42 & 41 & 205 \\
12,00 & - & 13,00 & 27 & 86 & 216 \\
13,00 & - & 14,00 & 27 & 156 & 221 \\
14,00 & - & 15,00 & 34 & 248 & 218 \\
15,00 & - & 16,00 & 60 & 298 & 221 \\
16,00 & - & 17,00 & 83 & 330 & 225 \\
17,00 & - & 18,00 & 96 & 317 & 230 \\
\hline
\end{tabular}

Berdasarkan Tabel 2, menunjukkan bahwa nilai akumulasi sepeda motor tertinggi pada hari senin sore hari jam 17.0018.00 sebanyak 230 kendaraan. Dari data tersebut dapat memperlihatkan dengan menggunakan sepeda motor dianggap lebih fleksibel. Adapun rekapitulasi akumulasi parkir mobil bisa dilihat pada Tabel 3.

Berdasarkan Tabel 3, menunjukkan nilai akumulasi parkir mobil tertinggi di hari senin pada pukul $16.00-17.00$ sebanyak 128 kendaraan, hal ini menggambarkan pengunjung pasar banyak beraktifitas pada hari kerja.

\section{b. Volume Kendaraan}

Volume parkir merupakan jumlah kendaraan yang parkir di suatu tempat atau kawasan parkir tertentu selama waktu tertentu pula. Volume kendaraan didapatkan dengan cara menjumlahkan kendaraan yang masuk lokasi parkir dengan kendaraan yang sudah ada secara kumulatif. Berdasarkan data survei dapat diketahui bahwa volume kendaraan mobil untuk hari Sabtu sebesar 105 kendaraan, hari minggu sebesar 119 kendaraan dan hari senin sebesar 245 kendaraan sedangkan volume untuk sepeda motor untuk hari sabtu sebesar 514 sepeda motor, hari minggu sebesar 633 sepeda motor dan untuk hari senin sebesar 751 sepeda motor[12].

Tabel 3. Rekapitulasi Akumulasi Parkir Mobil

\begin{tabular}{llcccc}
\hline \multicolumn{2}{c}{ Interval } & \multicolumn{3}{c}{ Akumulasi Parkir Pada Hari } \\
\multicolumn{2}{c}{} & & Sabtu & Minggu & Senin \\
\hline 6,00 & - & 7,00 & 65 & 51 & 112 \\
7,00 & - & 8,00 & 51 & 58 & 118 \\
8,00 & - & 9,00 & 37 & 70 & 120 \\
9,00 & - & 10,00 & 24 & 81 & 122 \\
10,00 & - & 11,00 & 14 & 90 & 124 \\
11,00 & - & 12,00 & 11 & 98 & 126 \\
12,00 & - & 13,00 & 9 & 102 & 127 \\
13,00 & - & 13,00 & 11 & 108 & 126 \\
14,00 & - & 15,00 & 14 & 115 & 125 \\
15,00 & - & 16,00 & 16 & 123 & 125 \\
16,00 & - & 17,00 & 19 & 131 & 128 \\
17,00 & - & 18,00 & 24 & 137 & 126 \\
\hline
\end{tabular}

\section{c. Durasi Parkir}

Durasi parkir merupakan lama rentang waktu sebuah kendaraan mobil atau mobil yang parkir di suatu tempat dalam satuan menit atau jam. Durasi parkir pasar Bintara dapat dihitung menggunakan interval tiap 1 jam seperti data survei yang didapatkan:

Durasi $<1$ Jam $=16$ sepeda motor;

$1-2 \mathrm{Jam}=21$ sepeda motor

2-3 Jam $=30$ sepeda motor

3-4 Jam $=15$ sepeda motor

4-5 Jam $=8$ sepeda motor

$5-6 \mathrm{Jam}=12$ sepeda motor

7-8 Jam $=10$ sepeda motor

9-10 Jam $=10$ sepeda motor

Adapun durasi parkir dapat dilihat pada Tabel 4. Berdasarkan Tabel 4, durasi rata-rata menyatakan rentang waktu sebuah kendaraan parkir di suatu tempat dalam satuan menit atau jam [2]. Durasi parkir dihitung menggunakan interval 1 jam, mengasumsikan para pengunjung di hari minggu banyak menitipkan kendaraannya untuk melanjutkan perjalanannya dengan menggunakan moda kereta api. Durasi parkir sepeda motor dapat kita lihat bahwa volume kendaraan pengunjung dengan durasi parkir paling banyak 1-2 dan 2-3 jam, namun kita dapat mengetahui durasi rata-rata dari keseleruhan pengunjung sebesar 8,6 jam. 
Tabel 4 Durasi Rata-rata Parkir Sepeda Motor Hari Senin

\begin{tabular}{cccccc}
\hline No & $\begin{array}{c}\text { Durasi } \\
\text { Parkir } \\
\text { (Jam) }\end{array}$ & $\begin{array}{c}\text { Nilai } \\
\text { Tengah } \\
(\mathrm{x})\end{array}$ & $\begin{array}{c}\text { Jumlah } \\
\text { Kendaraan } \\
\text { (f) }\end{array}$ & f.x & $\begin{array}{c}\text { Durasi } \\
\text { Rata- } \\
\text { Rata }\end{array}$ \\
\hline 1 & $0^{\prime}-1^{\prime}$ & 8 & 16 & 128 & \\
2 & $1^{\prime}-2^{\prime}$ & 10,5 & 21 & 220,5 & \\
3 & $2^{\prime}-3^{\prime}$ & 15 & 30 & 450 & \\
4 & $3^{\prime}-4^{\prime}$ & 7,5 & 15 & 112,5 & \\
5 & $4^{\prime}-5^{\prime}$ & 4 & 8 & 32 & 8,6 \\
6 & $5^{\prime}-6^{\prime}$ & 6 & 12 & 72 & \\
7 & $6^{\prime}-7^{\prime}$ & 5 & 10 & 50 & \\
8 & $7^{\prime}-8^{\prime}$ & 5 & 10 & 50 & \\
9 & $8^{\prime}-9^{\prime}$ & 5 & 10 & 50 & \\
10 & $9^{\prime}-10^{\prime}$ & 2 & 4 & 8 & \\
& & & & & \\
& Jumlah & & 136 & 1173 & \\
\hline
\end{tabular}

\section{d. Tingkat Pergantian Parkir (Turnover)}

Turnover merupakan angka pergantian kendaraan parkir dengan satuan kendaraan/SRP/Jam, diperoleh dengan membagi jumlah kendaraan atau volume parkir dengan jumlah ruang-ruang parkir/petak pada waktu periode tertentu. Parkir pasar Bintara tidak tertata jenis parkir, mengkhususkan parkir motor maupun mobil. Data survei menunjukkan $20 \%$ pengunjung menggunakan mobil dan $80 \%$ menggunakan sepeda motor. Berdasarkan hal itu penulis dalam menganalisa difokuskan menggunakan data hari senin, dengan mempertimbangkan jumlah pengunjung lebih banyak dari pada hari survei lainnya.

\section{e. Kapasitas Parkir}

Kapasitas parkir merupakan banyaknya jumlah maksimum kendaraan yang bisa di layani pada suatu lahan atau kawasan parkir. Besar kecilnya suatu kapasitas parkir akan menentukan jumlah kendaraan yang dapat ditampung [12].

Kapasitas Parkir $=221 / 6,2=35,6$ atau $36 \mathrm{SRP} / \mathrm{Jam} /$ Kendaraan. Dengan perhitungan yang sama untuk kapasitas sepeda motor didapatkan 103 SRP/Jam/Kendaraan.

\section{f. Indeks Parkir}

Indeks parkir merupakan perbandingan antara akumulasi parkir dengan kapasitas parkirnya. Contoh perhitungan misalnya parkir mobil hari senin

Akumulasi Parkir $=39$ kendaraan

Kapasitas Parkir $=36 \mathrm{SRP} / \mathrm{Jam} /$ Kendaraan

Indeks Parkir $\quad=(39 / 36) \times 100 \%=108 \%$

Dengan cara yang sama untuk sepeda motor pun di dapatkan 93\% sehingga parkir mobil perlu penanganan dalam kebutuhan ruang parkir.

\section{Retribusi Parkir}

Pembangunan dan penyelenggaraan pemerintah di daerah diperlukannya pembiyaan dalam menjalankan pemerintahan untuk itu pemerintah daerah akan mengoptimalkan pendapatan asli daerah (PAD), berupaya memperdayakan sektor swasta dalam membiayai kegiatan pembangunan [13], sumber pendapatan daerah didapatkan dari pajak daerah, retribusi daerah, hasil pengelolaan kekayaan dan lainnya. Retribusi memberikan kontribusi namun pengelolaan tiap daerah berbeda-beda [11]. Retribusi pasar Bintara serta retribusi parkir sebagai salah satu penerimaan daerah yang cukup berarti di kota Bekasi [13]. Analisa kontribusi [14], retribusi parkir digunakan untuk mengetahui kontribusi dari penerimaan retribusi parkir dalam mendukung pendapatan daerah. Analisis ini dihitung dengan cara membandingkan antara realisasi penerimaan retribusi parkir dengan realisasi penerimaan pendapatan asli daerah (PAD). Hasil nilai karakteristik parkir tersebut didapatkan berdasarkan data pengambilan pada masa pandemik Covid 19, pengunjung ke lokasi berkurang mengakibatkan jumlah kendaraan pun mengalami penurunan, dengan demikian perencanaan diasumsikan dalam optimalisasi konektivitas berdasarkan trandline penambahan daya tampung/kapasitas pada lahan parkir tersebut. Adapun asumsi perencanaan daya tampung lahan parkir pasar Bintara:

a. Mobil Pribadi berjumlah 250 kendaraan

b. Sepeda Motor berjumlah 850 kendaraan

c. Mobil Truck berjumlah 6 unit

d. Mobil Angkutan kota berjumlah 12 unit

e. Sepeda berjumlah 100 unit

Sehingga potensi pendapatan parkir sebesar
a. Motor $850 \times \mathrm{Rp} 3.000=\mathrm{Rp} 2.550 .000$
b. Mobil $250 \times$ Rp $5.000=R p 1.250 .000$
c. Truck $6 \quad$ x Rp $10.000=\operatorname{Rp} 60.000$

Total Pendapatan perhari $=$ Rp 3.860 .000

Dari analisa tersebut kontribusi parkir perhari pada kawasan parkir pasar Bintara mendapatkan $\mathrm{Rp} 3.860 .000$ atau $\mathrm{Rp}$ $115.800 .000 /$ bulan.

\section{Desain konektivitas antara Stasiun Cakung dan Pasar Bintara}

Stasiun Cakung berdekatan dengan pasar Bintara, fasilitas pejalan kaki di kawasan tersebut menjadi hal yang sangat penting bagi pejalan kaki, untuk memberikan pelayanan. Penyebrangan jalan salah satu fasilitas dalam meningkatkan kelancaran, keselamatan, keamanan dan kenyamanan pejalan kaki saat menyebrangi jalan. Analisa penentuan desain konektivitas antara stasiun Cakung dengan pasar Bintara 
berdasarkan data survai hari senin dikarenakan hari tersebut menunjukan pergerakan transportasi yang aktif di lokasi penelitian tersebut. Hasil survai arus pejalan kaki yang melewati ruas dari arah stasiun Cakung ke pasar Bintara dan pasar Bintara ke stasiun Cakung memperlihatkan puncak arus lalu lintas kendaraan terjadi pukul 13.30-13.14 dengan jumlah kendaraan sebesar 94 kendaraan dan jumlah total volume kendaraan dari jam $06.00-18.00$ WIB berjumlah 1803 kendaraan, yang dapat dilihat pada Tabel 5.

Tabel 5 Volume Arus Kendaraan Hari Senin

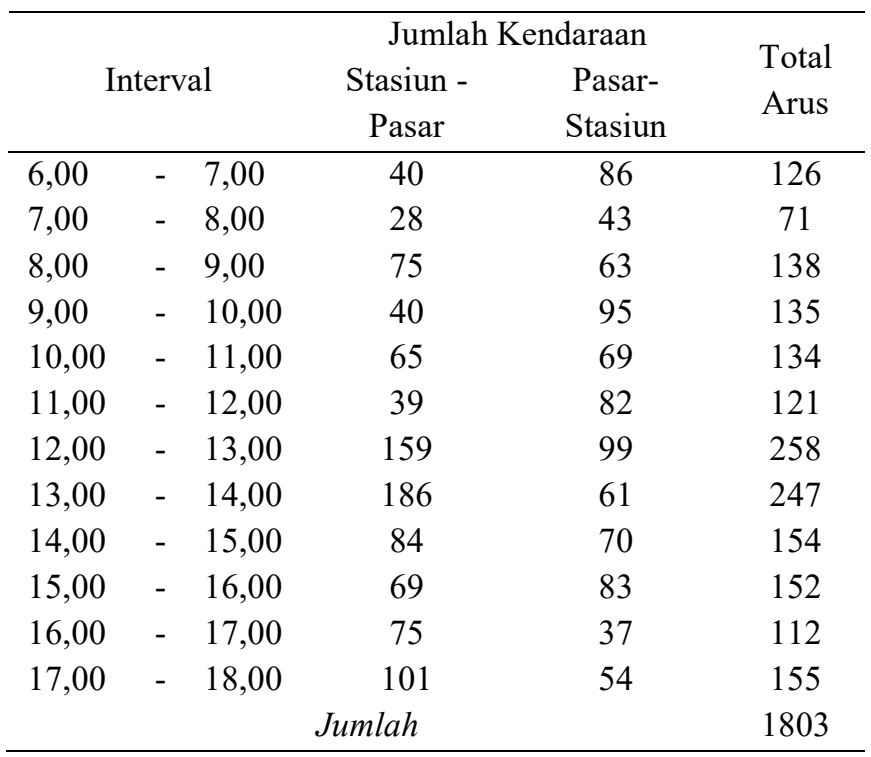

Berdasarkan data arus pejalan kaki dan data volume arus lalu litas pada data survei kemudian dikompilasikan dengan metode Departemen Jendral Bina Marga 1995 (Tata Cara Perencanaan Fasilitas di daerah perkotaan) dalam penentuan pilihan penyebrangan jalan [15], maka menunjukkan jenis penanganan konektivitasnya. Dalam penelitian ini dapat dilihat data jumlah total penyebrangan $(\mathrm{P})=1153$ orang dan jumlah total volume kendaraan (V) sebesar 1803 kendaraan maka nilai $\mathrm{PV}^{2}=1153 \times(1803)^{2}=3,7 \times 10^{6}$ maka nilai ini termasuk pada tipe fasilitas konektivitas pasar cakung dengan stasiun menggunakan Zebra Cross (Zc). Adapun gambar desain Zebra cross yang dapat diterapkan pada jalan penghubung konektivitas dapat dilihat di Gambar 4.

Berdasarkan Gambar 4, menunjukkan desain Zebra Cross dibuat lebar 2,5 meter dengan desain garis hitam putih berjarak 0,3 meter.

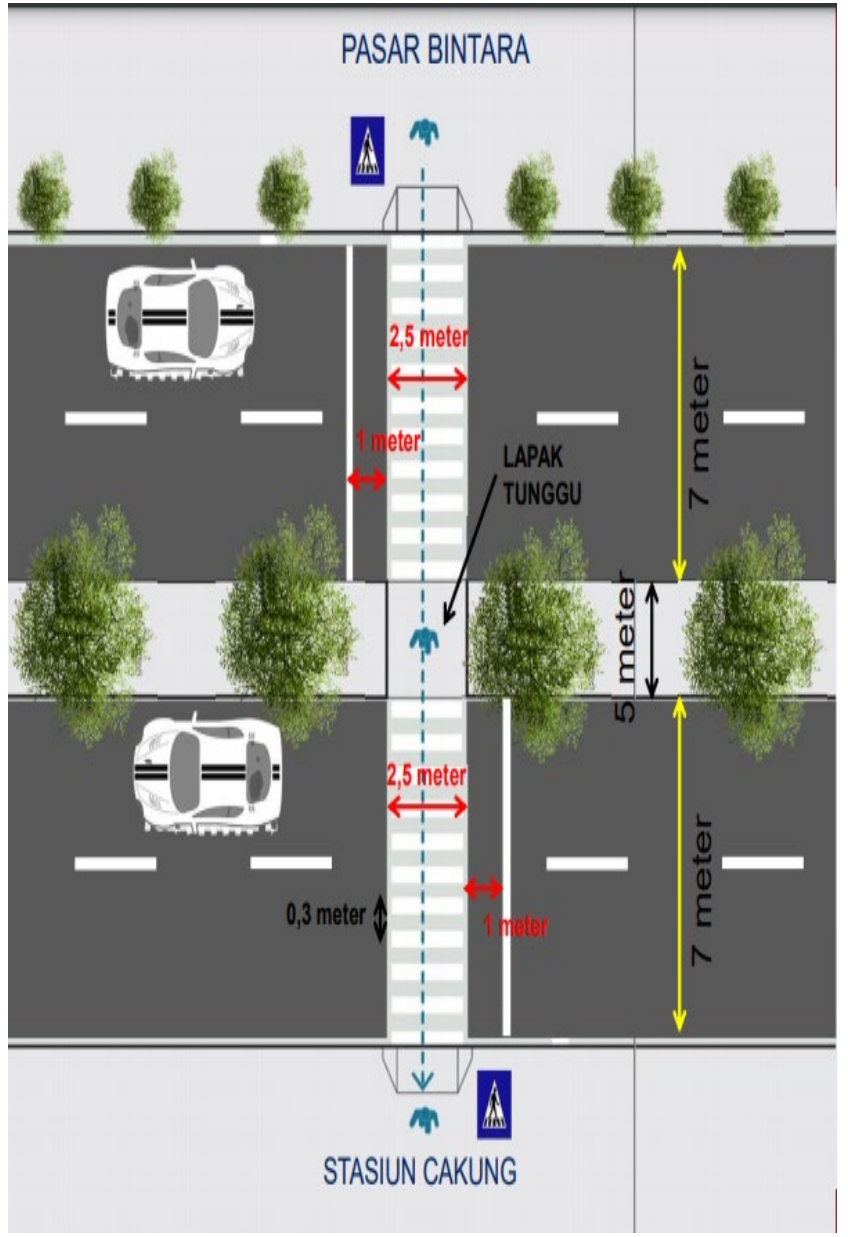

Gambar 4. Desain Zebra Cross

Biaya Penanganan Optimalisasi konektivitas Pasar Bintara dengan Stasiun Cawang

Optimalisasi konektivitas menjadi peranan penting dalam perkembangan daerah, dengan demikian penanganan optimalisasi pasar Bintara ini dilakukan dengan penambahan ruang parkir, perbaikan lahan parkir dan fasilitas penyebrangan orang Zebra Cross. Adapun anggaran biaya yang dibutuhkan sesuai sub pekerjaan sebagai penanganan optimalisasi konektivitas pasar Bintara dengan stasiun Cawang meliputi pekerjaan persiapan pembongkaran bangunan, pembongkaran median existing, mobilisasi dan demobilisasi, pekerjaan perkerasan area parkir, pembuatan tack coat, lapis Ac-Wc, sedangkan pekerjaan pembuatan zebra cross terdiri dari pemasangan bollard, pengecetan zebra cross dan rabat beton di median jalan serta pekerjaan finising berupa pengecatan marka parkir dan pembuatan rambu-rambu, dengan volume pekerjaan yang telah diperhitungkan terlebih dahulu. Rekapitulasi anggaran biaya dapat dilihat pada Tabel 6. 
Tabel 6. Rekapitulasi Anggaran Biaya Konektivitas Pasar Bintara dengan Statsiun Cakung

\begin{tabular}{|c|c|c|c|c|c|}
\hline No & Uraian Pekerjaan & Satuan & Volume & $\begin{array}{l}\text { Harga Satuan } \\
\text { (Rp) }\end{array}$ & $\begin{array}{c}\text { Jumlah Harga } \\
\text { (Rp) }\end{array}$ \\
\hline A & Pekerjaan Persiapan & & & & \\
\hline 1 & Pembokaran Bangunan & Ls & 1 & 20.000 .000 & 20.000 .000 \\
\hline 2 & Pembokaran Median Exsisting & Ls & 1 & 2.000 .000 & 2000.000 \\
\hline 3 & Pengukuran & Ls & 1 & 5.000 .000 & 5.000 .000 \\
\hline 4 & Mobilisasi dan demobilisasi & Ls & 1 & 10.000 .000 & 10.000 .000 \\
\hline B & Pekerjaan Perkerasan Area Parkir & & & & \\
\hline 1 & Tack Coat & Ltr & 20.000 & $18.009,53$ & 360.190 .600 \\
\hline 2 & Lapis Ac-Wc tebal $6 \mathrm{~cm}$ & $\mathrm{~m}^{3}$ & 995,03 & $1.670 .970,40$ & 1.662 .658 .325 \\
\hline $\mathrm{C}$ & Pekerjaan Zebra Cross & & & & \\
\hline 1 & Pengecetan Zebra Cross & $\mathrm{m}^{2}$ & 70.00 & 300.000 & 21.000 .000 \\
\hline 2 & Pemasangan Bollard & unit & 10.00 & 2.500 .000 & 25.000 .000 \\
\hline 3 & Rabat Beton di median jalan & $\mathrm{m}^{3}$ & 3,75 & 850.000 & 3.187 .500 \\
\hline $\mathrm{D}$ & Pekerjaan Finishing & & & & \\
\hline 1 & Pengecetan marka parkir & ls & 1 & 20.000 .000 & 20.000 .000 \\
\hline \multirow[t]{2}{*}{2} & Pembuatan rambu-rambu & unit & 20 & 1.500 .000 & 30.000 .000 \\
\hline & & Total & & & 2.159 .036 .425 \\
\hline
\end{tabular}

Berdasarkan Tabel 6, menunjukkan total biaya yang diperlukan dalam optimalisasi konektivitas pasar Bintara dengan stasiun Cakung sebesar Rp 2.159.036.425.

\section{Simpulan}

Berdasarkan hasil analisis dan pembahasan data-data hasil parkir pasar Bintara dan Stasiun Cawang dapat disimpulkan bahwa karakteristik parkir pasar Bintara menunjukan nilai akumulasi parkir sepeda motor tertinggi ada di hari senin pukul 17.00-18.00 WIB sebanyak 230 kendaraan sedangkan akumulasi mobil pada hari yang sama pukul 16.00-17.00 WIB sebanyak 128 kendaraan, volume parkir sepeda motor lebih banyak dari pada mobil sebanyak 751 kendaraan hal ini menunjukkan bahwa sepeda motor dianggap kendaraan yang fleksibel, durasi parkir sepeda motor pengunjung paling banyak 1-2 dan 2-3 jam namun durasi rata-rata dari keseluruhan menunjukan pengunjung sebesar 8,6 jam, tingkat pergantian parkir, kapasitas parkir sepeda motor menunjukkan $103 \mathrm{SRP} / \mathrm{Jam} /$ Kendaraan sedangkan kapasitas parkir mobil menunjukkan 35,6 $\mathrm{SRP} / \mathrm{Jam} /$ Kendaraan sehingga dengan data tersebut indek parkir dapat terlihat melebihi dari persyaratan yang ditentukan maka perlu penanganan perbaikan parkir sebagai perencanaan penanganan optimalisasi konektivitas pasar Bintara dengan stasiun Cawang dengan penambahan daya tampung parkir sebagai berikut: mobil pribadi berjumlah 250 kendaraan, sepeda motor berjumlah 850 kendaraan, mobil truck berjumlah 6 unit, mobil angkutan kota berjumlah 12 unit dan sepedah berjumlah 100 unit serta pembuatan fasilitas penyebrangan orang dengan menggunakan desain Zebra Cross sehingga membutuhkan total anggaran biaya sebesar $\mathrm{Rp} 2.159 .036 .425$,- maka potensi pendapatan retribusi parkir Motor $850 \times \mathrm{Rp} 3.000,-=\mathrm{Rp}$ 2.550.000,- ; Mobil $250 \times$ Rp 5.000,- = Rp 1.250.000,- ; Truck 6 x Rp 10.000,- = Rp 60.000,- maka total pendapatan perhari $=\operatorname{Rp} 3.860 .000$,- atau $R p$ 115.800.000,-/bulan.

\section{Daftar Pustaka}

[1] M. Z. Arifin, "Analisa Efektifitas Fasilitas Zebra Cross pada Jl. Mt Haryono dan Jl. Gajayana," $J$. Chem. Inf. Model., vol. 53, no. 9, pp. 1689-1699, 2013.

[2] H. F.D, Perencanaan dan Teknik Lalu lintas. Yogyakarta. Gajah Mada University Press anggota IKPI. Institute of Transportation Engineering Washington DC, 1995.

[3] D. P. D. jendral P. Dara, "Persyaratan teknis Bangunan Stasiun Kereta Api," 2011. [Online]. Available: htpp//hubdat.dephub.go.id.

[4] N. Widyaningsih and O. Daniel, "Analisis Karakteristik Dan Perilaku Penyeberangan Orang Pada Fasilitas Penyeberangan Zebra Cross Dan Pelican Cross (Studi Kasus Ruas Jalan M. H. Thamrin)," J. Pengemb. Rekayasa dan Teknol., vol. 15, no. 1, p. 27, 2019.

[5] S. dan I. B. Mariani, "Karakteristik Kebutuhan Parkir 
Pada Hotel Bintang Tiga di Makassar," Tek. Sipil Fak. Tek. Univ. Hasanuddin, 2010.

[6] Stupa, "Analisia Karakteristik dan Permodelan Kebutuhan Parkir Pada Pusat Perbelanjaan di Kota Denpasar," J. Tek. Sipil, vol. 12, 2016.

[7] I. dkk Abubakar, Pedoman Perencanaan dan Pengoperasian Fasilitas. Jakarta: Direktorat Bina Sistem Lalu Lintas Angkutan Kota, 1998.

[8] J. Parmar, P. Das, F. Azad, S. Dave, and R. Kumar, "Evaluation of Parking Characteristics: A case study of Delhi," Transp. Res. Procedia, vol. 48, no. 2019, pp. 2744-2756, 2020.

[9] T. Rosdiyani, "Kajian Kebutuhan Ruang Parkir Sebagai Pengendali Lalu Lintas Di Kampus Universitas Muhammadiyah Surakarta," 2013.

[10] Kementerian Pekerjaan Umum dan Perumahan Rakyat, "Pedoman Bahan Konstruksi Bangunan dan Rekayasa Sipil: Perencanaan Teknis Fasilitas Pejalan
Kaki," SE Menteri PUPR, pp. 5-6, 2017.

[11] Departemen Jendral Bina Marga, ( Tata Cara Perencanaan Fasilitas di daerah perkotaan. 1995.

[12] Dayana, "Analisis Kebutuhan Parkir Kendaraan di Bandara Husein Sastranegara," ITB, 2012.

[13] C. P. Chu, C. Y. Wang, and S. R. Hu, "Application of E-Tag in Pricing Road Tolls and Parking Fees for Traffic Congestion Mitigation," Transp. Res. Procedia, vol. 25, pp. 2913-2922, 2017.

[14] S. Y. . T. Toar Waraney Lakoy, Daisy S.M Engka, "Kontribusi Dan Pengaruh Penerimaan Retribusi Daerah Terhadap Pendapatan Asli Daerah Di Kabupaten Minahasa Selatan (2005-2014)," J. Berk. Ilm. Efisiensi, vol. 16, 2014.

[15] A. Nusa, S. Falah, and I. K. Wamafma, "Potensi Pajak Dan Retribusi Daerah Di Kabupaten Yahukimo," J. Keuda, vol. 2, no. 3, pp. 1-17, 2015. 